\title{
ArcheoSciences
}

Revue d'archéométrie

33 (suppl.) | 2009

Mémoire du sol, espace des hommes

\section{Geophysical methods in the research of archaeological sites in Western Siberia and Altai: results and perspectives}

Michail I. Epov and Marina A. Chemyakina

\section{(2) OpenEdition Journals}

Electronic version

URL: https://journals.openedition.org/archeosciences/1682

DOI: 10.4000/archeosciences.1682

ISBN: 978-2-7535-1599-4

ISSN: $2104-3728$

Publisher

Presses universitaires de Rennes

\section{Printed version}

Date of publication: 30 October 2009

Number of pages: $271-274$

ISBN: 978-2-7535-0943-6

ISSN: $1960-1360$

\section{Electronic reference}

Michail I. Epov and Marina A. Chemyakina, "Geophysical methods in the research of archaeological sites in Western Siberia and Altai: results and perspectives", ArcheoSciences [Online], 33 (suppl.) | 2009, Online since 30 October 2011, connection on 01 February 2022. URL: http://journals.openedition.org/ archeosciences/1682 ; DOI: https://doi.org/10.4000/archeosciences.1682 


\title{
Geophysical methods in the research of archaeological sites in Western Siberia and Altai: results and perspectives
}

\author{
Michail I. Epov* and Marina A. Chemyakina**
}

Key words: Archaeology of Western Siberia and Altai, Burial mounds, Pazyryk, Magnetometry, Electromagnetic sounding, Gas chromatography.

A joint team from the Institute of Archaeology and Ethnography SB RAS and the Institute of Petroleum Geology and Geophysics has performed geophysical and archaeological studies at archaeological sites in Western Siberia and Altai.

Studies of different kinds of archaeological sites using magnetometry, near-surface electromagnetic frequency induction sounding (NEMFIS), the resistivity method and geopenetrating radar allowed the effectiveness and productivity of various techniques to be compared, as well as assessing the results of the combined application and determining optimal sets of geophysical techniques for different kinds of archaeological sites taking into consideration various types of soils.

The search for cult-related objects and settlements was successful; ancient burials not evidenced on the surface were also found. Geophysical methods were developed for penetrating the "frozen" mounds of Pazyryk and proven archaeologically to be effective. Further research is aimed at developing techniques for identifying wooden structures inside the stone burial chambers under the mounds.

Magnetometric mapping of the Preobrajenka-6 site (Novosibirsk area) was done with a G-858 gradiometer along measurement lines $1 \mathrm{~m}$ apart. The total exploration area covered 12,800 square meters. Magnetic anomalies believed to be caused by archaeological objects were observed. The main part of the site was identified as a burial ground already prior to the work and geophysical exploration was intended as a means of identifying the eastern and northern boundaries of the site, and deciding on an optimal strategy for further archaeological investigations testing the magnetic results (Fig. 1). The relation between magnetic parameters, depth, and character of burial pit fillings was studied (Djadkov et al., 2005).

Magnetometry mapping at the Preobrajenka-2 site (Novosibirsk area) covered 28,800 square meters and included a soil structure $80 \mathrm{~m}$ in diameter seen on the ground as well as surrounding structures, partly in ploughed fields. The surface collection of artifacts from the ploughed fields is attributed to an Irmen culture settlement (12th-11th century $\mathrm{BC})$. The idea was to check the settlement structure against ground topography before excavation, but agricultural activities have disturbed the remains of ancient buildings, resulting in a weak magnetic contrast between archaeological objects and surrounding soil. While magnetometry is the best tool for mapping widespread archaeological sites, it is useless when the ground topography reveals the presence of structures or when the magnetic contrast is insufficient. Electromagnetic

* Trofimuk Institute of Petroleum-Gas Geology and Geophysics of SB RAS, Koptyug Ave, 3, Novosibirsk 630090, Russia. (Epov@uiggm.nsc.ru)

** Institute of Archaeology and Ethnography SB RAS, Lavrentiev Ave 17, Novosibirsk 630090, Russia. (chemyakina@archaeology.nsc.ru) 


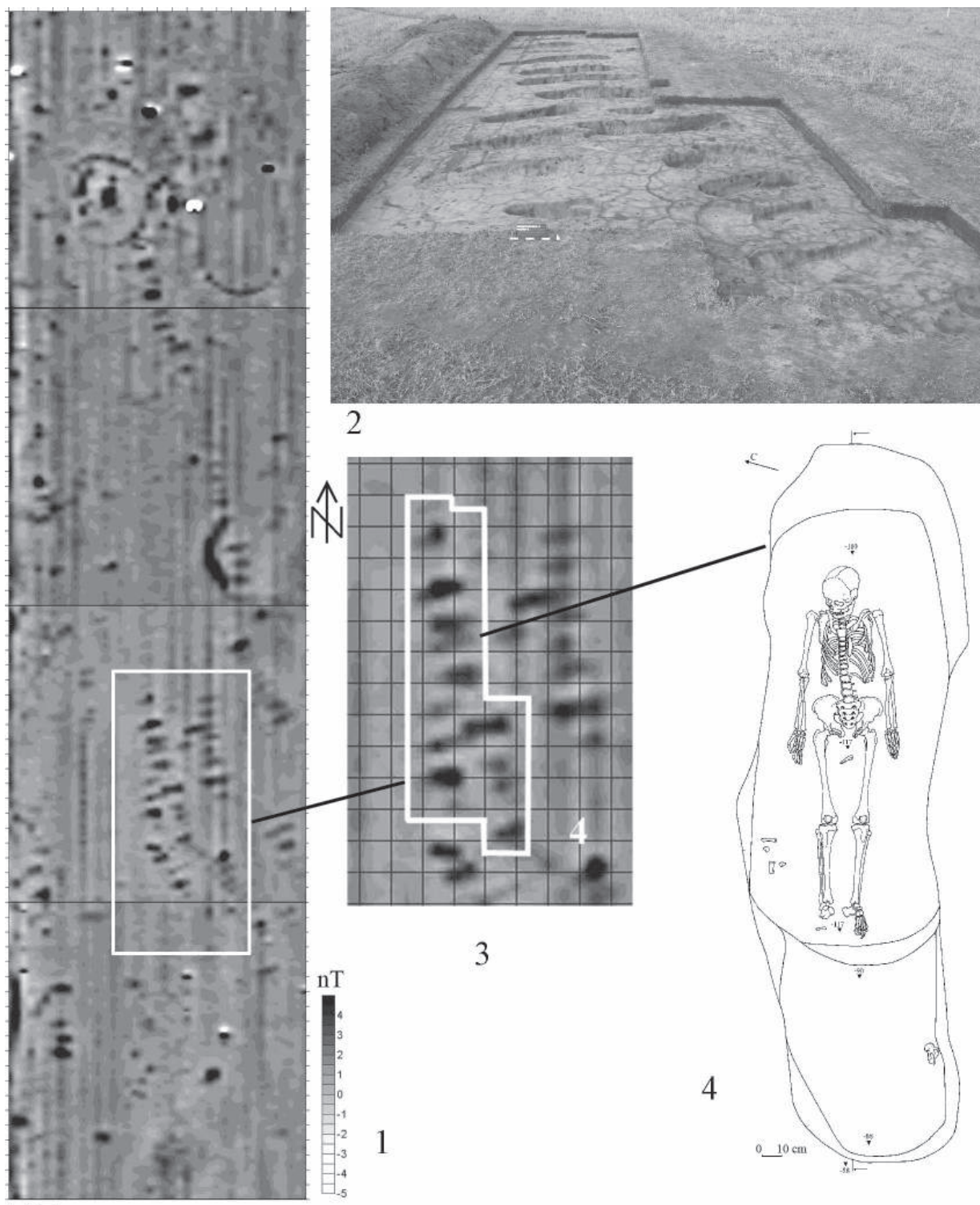

Figure 1: Preobrajenka-6: 1 - central and northern sides of the site magnetogram; 2 - excavation of mound $\mathrm{n}^{\circ} 4$, view from the south; 3 - excavation $\mathrm{n}^{\circ} 4$ magnetogram; 4 - plan of burial $n^{\circ} 3$. sounding is not as quick as a method, but is less affected by noise. The complementariness of the two methods makes their joint use increasingly effective. Adding an electromagnetic induction frequency sounding to the survey program helped to specify anomalies caused by Irmen dwelling remains (Fig. 2). Partly, in the south, these habitations are covered by the circular soil structure. Before excavation, this structure was suggested to be constructed later than the buildings below.

Mathematic simulation of expected objects was performed prior to geophysical technique adjustment based on the results of permafrost research inside the burial mounds on the Ukok plateau (Altai Mountains). Three Pazyryk burial mounds were chosen for testing the results, the first one apparently containing a permafrost target, the second free of ice and frozen ground. Using the original modification of electric profiling together with electromagnetic shallow depth induction sounding provided an image of a lowconductive anomaly inside the first mound. The anomaly probably corresponds to permafrost deep in the mound. An analysis of the collected data indicated that only one of the three explored mounds ( ${ }^{\circ} 4$ in the Verkh-Kaldjin-II system) contains a non-conductive anomaly in the center (Fig. 3), shaped like the expected burial chamber in frozen ground.

The conventional DC electric profiling method was customized taking into consideration the impossibility of galvanic contact with the ground on the top of the Pazyryk burial mound because of the big-stone cover. The customization allows ground contact to be made outside the mound. 
Figure 2: Results of geophysical research at Preobrajenka-2: 1 - magnetogram; 2 - NEMFIS geoelectric map $(40 \mathrm{kHz}), 1 \times 2$ m grid.

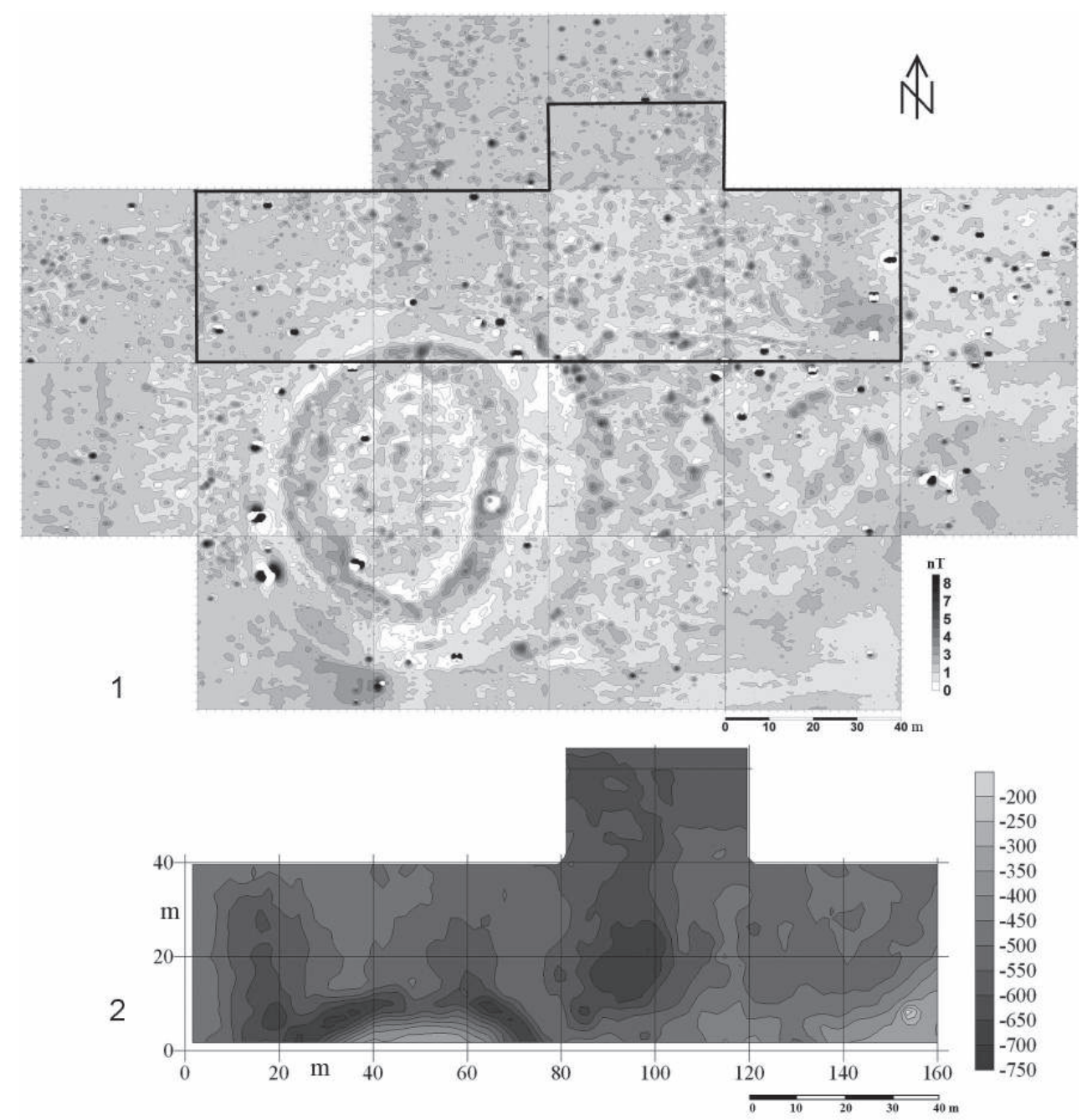

The Near-Surface Electro Magnetic Frequency Induction Scanner (NEMFIS) (Balkov, et al., 2006) has been developed by the Institute of Geophysics of the Russian Academy of Sciences (IPGG SB RAS). It is a portable three-coils EM-I sensor working in the $2.5-250 \mathrm{kHz}$ range. Operating at 14 frequencies on every station, NEMFIS is able to collect data to build up to 14 maps or $3 \mathrm{D}$ pictures. The measured signal is proportional to electric conductivity. In conductive media $(1-200 \mathrm{Ohm} \cdot \mathrm{m})$, it is possible to convert the NEMFIS data into apparent resistivity that corresponds to specific conductivity. Pazyryk burial mounds and accommodating media feature higher resistivity, hence the NEMFIS apparent resistivity could be considered only as a qualitative image of resistivity distribution in this case. Still, the qualitative image is very useful and reflects the inner structure of the burial mounds.

The method of ice research was developed by the authors, tested and proved by excavations in 2005-2007 in Mongolia. The predicted presence of ice lenses inside the mounds was

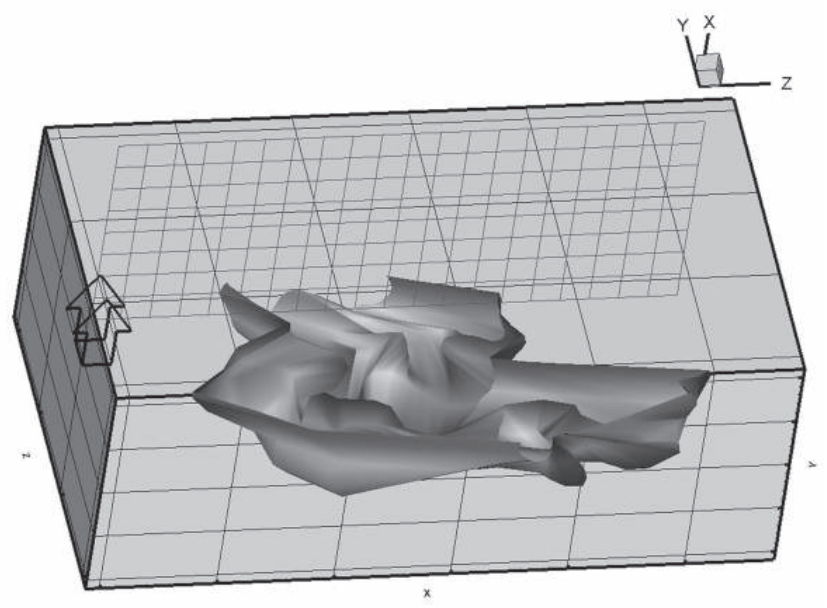

Figure 3: Mound $n^{\circ} 4$ at Verkh-Kaldjin-II. The ice anomaly object in NEMFIS data: isosurface of $1500 \mathrm{Ohm} \times \mathrm{m}, 0.5 \times 0.5 \mathrm{~m}$ grid. 
verified in every case. However, the origin of ice lenses was not always associated with ancient burial. In the Ulan-Daba mound, ice was present for natural reasons. Geophysical identification of wooden structures inside ice lenses is problematic at best.

Burial mounds Bertek-1 and 10, Verkh-Kaldjin-2, 3 and 13 , and Kaldjin- 6 on the Ukok plateau were investigated in 2007 using the following geophysical methods: NEMFIS, susceptimetry with MP-01, geopenetrating radar GROT-12, gamma-spectrometry with MKS AT $6101 \mathrm{D}$, gas chromatography with ECHO-FID. The preprocessed data shows that ice lenses can be found in mound $n^{\circ} 4$ at Verkh-Kaldjin2 , in the western part of mound $n^{\circ} 3$ and the central part of mound $n^{\circ} 4$ at Verkh-Kaldjin-3. The feasibility of the identification of ice and larch-wood prior to excavation by remote geophysical and geochemical methods has been proved (Epov et al., 2008).

Burial mounds are the most complicated target for geophysical surveys and archaeological interpretation. Due to the large diversity of mound soil composition and structure, their geoelectric and magnetic features are very different. Remote survey of such targets requires further development of geophysical methods, techniques, devices and approaches.

\section{References}

Balkov, E. V., Manstein, A. K., Chemyakina, M. A., Manstein, YU A. and Epov, M. I., 2006. An experience of using frequency-domain EMI soundings for archaeological geophysical applications. Geophysics, 1: 43-50.

Djadkov, P. G., Molodin, V. I., Chemyakina, M. A. and Mikheyev, O. A., 2005. Magnetometry of Tartas-1 and Preobrajhenka-6 in Barabinsk forest-steppe. Problems of Archeology, Ethnography, Anthropology of Siberia and Adjacent Territories XI, 304-309.

Epov, M. I., Molodin, V. I. and Chemyakina, M. A., 2008. Diagnostics of structure of the "frozen" barrows, Pazyryk cultures of Altai, geophysical and geochemical methods. Works of II (XVIII) All-Russia congress in Suzdal III, Moscow, 416-419. 